\title{
MELMERBY RESEARCH RESTORATION
}

C.D.R. MACGREGOR

Martec Limited, Halifax, Nova Scotia, Canada

INTRODUCTION

Melmerby Beach in Pictou County, Nova Scotia, (Fig. 1) is one of the few class-one sand beaches in the province. It is a very popular recreational beach which, at times, can have 4000 to 5000 people occupying its one-mile length. This heavy, and until now unplanned, recreational use has caused deterioration of the beach in width.

Melmerby Beach is a tombolo connecting the mainland to Roy's Island, about one mile distant (Fig. 2). The beach is a result of the retreat of the glaciers and corresponding rise in sea level. Glacial debris was re-worked and washed inshore until the shallow area of an old river mouth (now Little Harbour) was reached and a bar formed. As more sand from the glaciated sandstone of this region was washed up, the bar eventually became a beach connecting Roy's Island (a drumlin) to the mainland.

The formation of this beach appears to be fairly recent (last few hundred years), but once initiated, the beach widened rapidly and became well vegetated with dune grasses and shrubs. By the early 1900's, the beach was over 400 feet wide along its whole length (Fig. 3). Even at this time people visited the area for picnicking, and sand was hauled away for use in the coal mines at nearby Stellarton. Roy's Island was farmed then and a road ran along the back of the beach to provide access to the Island.

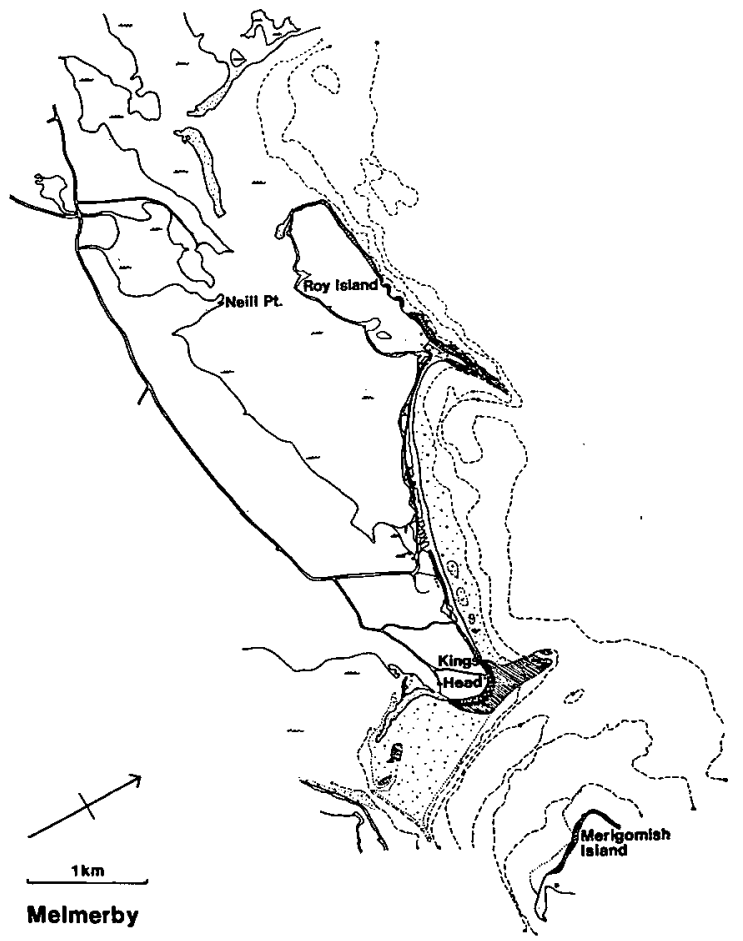

FIG. 2 Melmerby Beach Area.

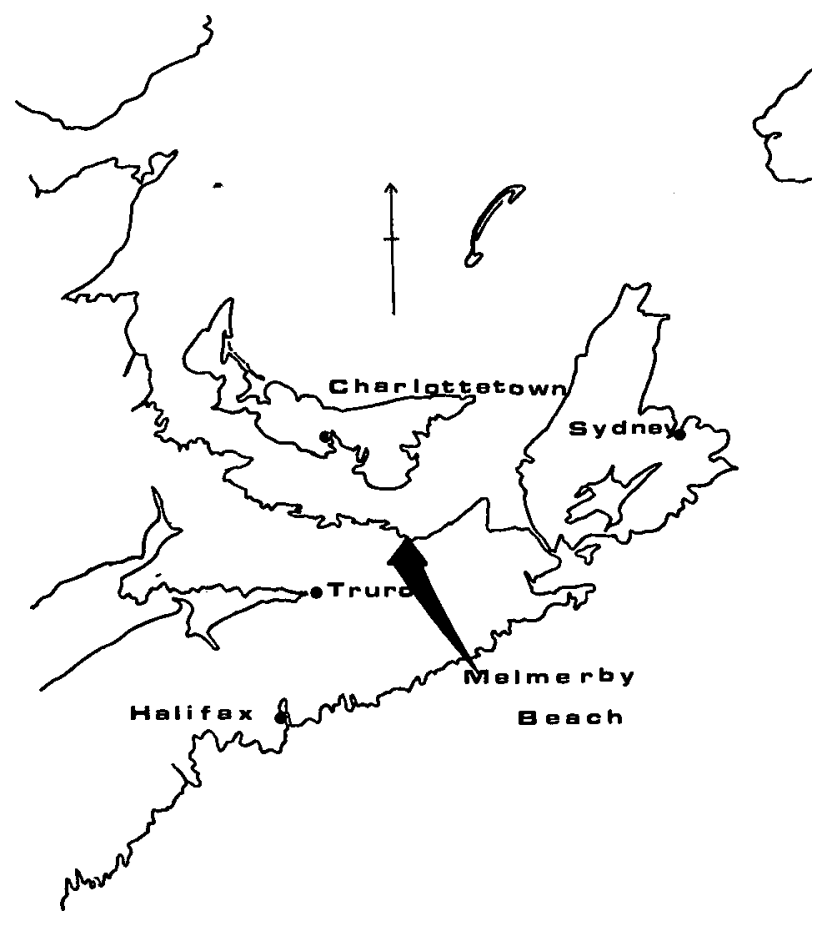

FIG. I Location of Melmerby Beach

THE PROBLEM

As time passed, recreational use and sand mining increased. It is estimated that over 750,000 tons of sand were mined from the beach for constructional use and sanding the highways. This severely damaged the beach by leaving unvegetated holes that allowed sand to blow away or be washed away in winter storms. Recreational use became more oriented toward the motor vehicle and "dune buggying".

People using the beach had been parking cars very near the crest of the dunes, destroying vegetation. and also driving over the dunes to "dune buggy" on the beach. This resulted in destruction of the dune grass (Ammophila breviligalata) that functioned to trap and hold sand in place on the dunes. The result was the loss of this sand causing numerous blowouts on the beach. Due to heavy traffic, these gaps in the dunes never re-vegetated, and sand blown up the beach. by the fall winds, blew across the narrow beach to settle on the back of the beach in Little Harbour. Since transport by wind was from the northeast during the fall, this resulted in a severe deprivation of sand to the western end of the beach, as it blew through the beach. instead of down the beach. This end was the first place to fail under winter storms.

MARITIME SEDIMENTS, April 1977, Vol. 13, No. 1, pp. 3i-36 
The net result was a severe thinning and recession of the beach as shown by comparison of beach drawings for 1945 and 1971 (Fig. 4). The weakened beach and dune system started to break under winter storms, breaking at the western end of the beach in 1967-1968, 1970-1971, and most recently in October of 1974.

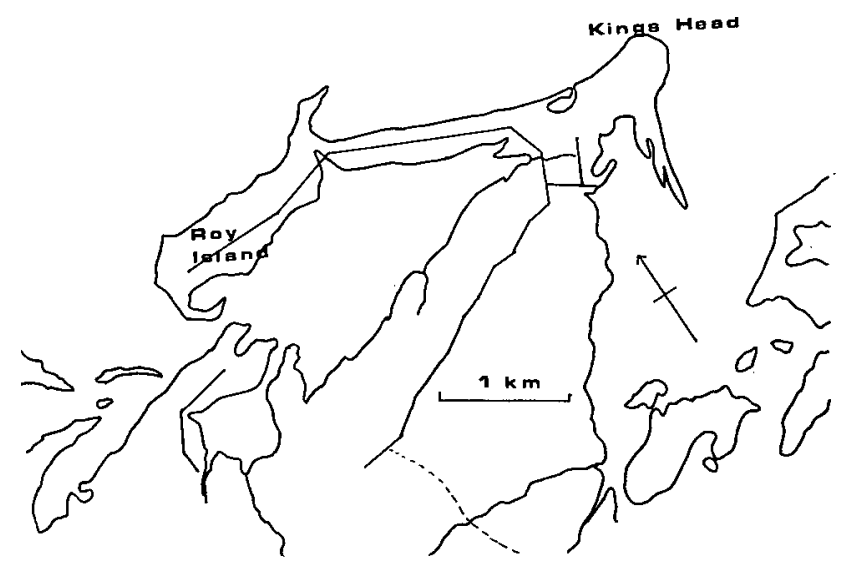

FIG. 3 Melmerby Beach, 1879.

FIG. 4 Melmerby Beach Recession.

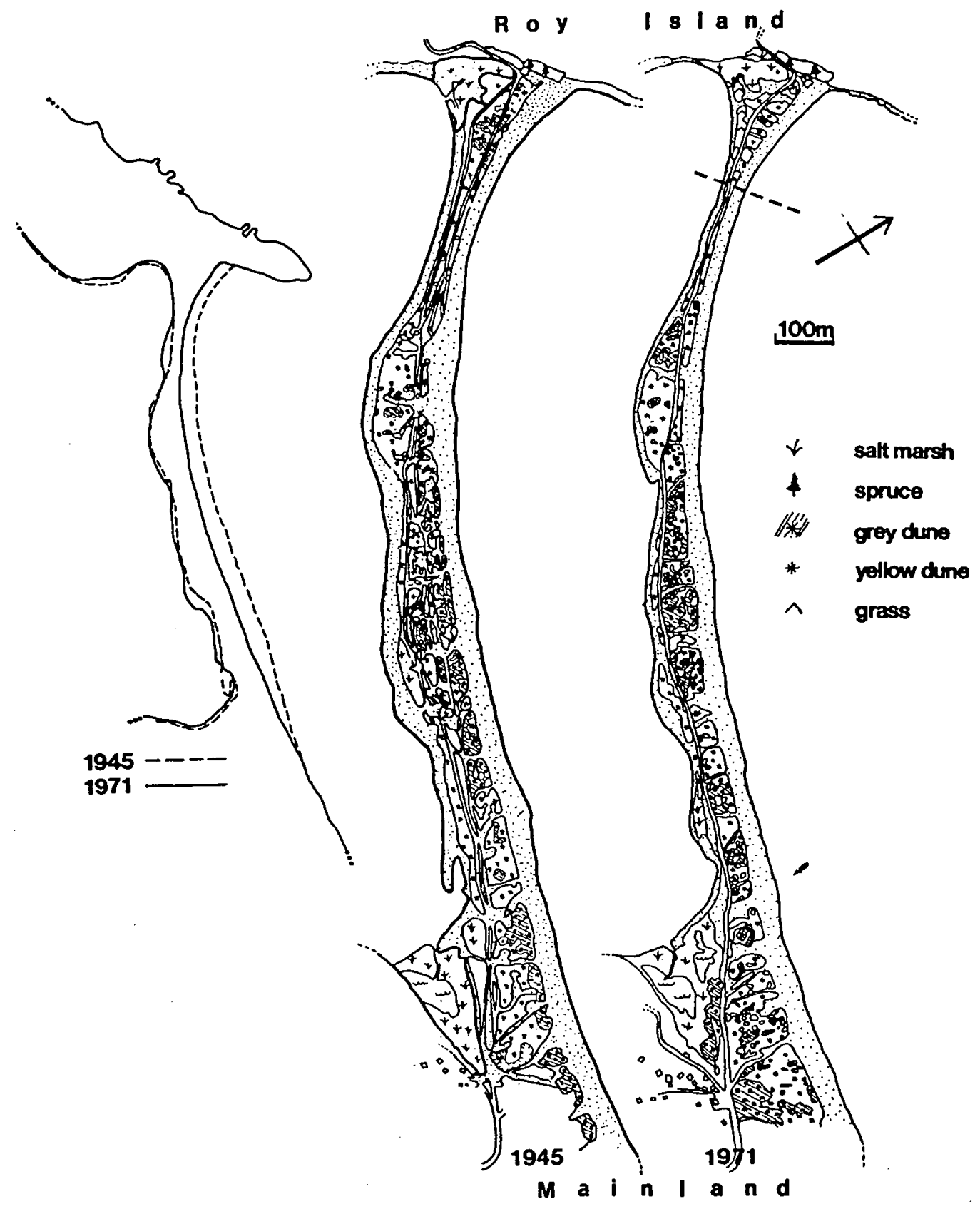




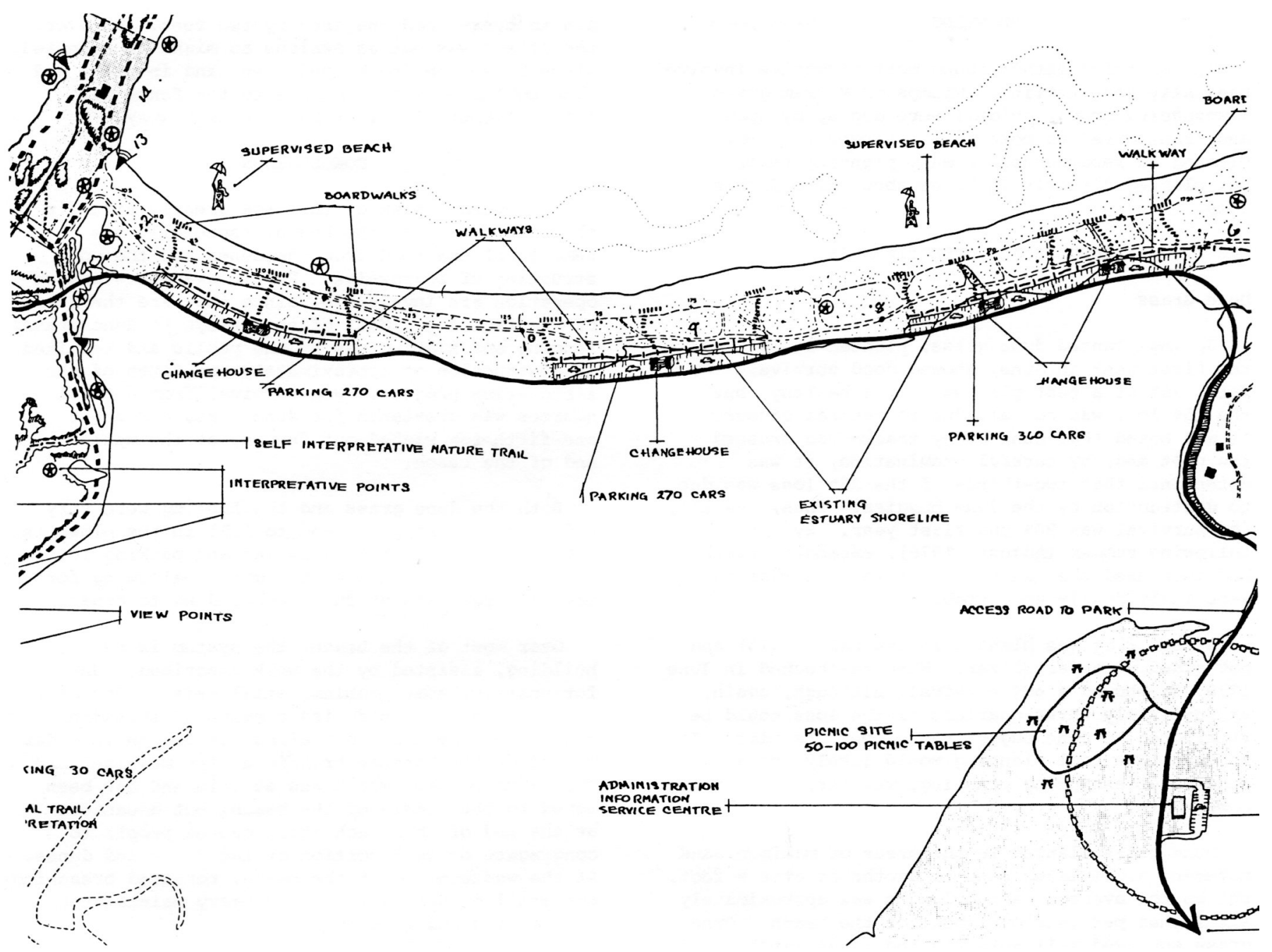

FIG. 5 Master Plan for Melmerby Beach.

THE PLAN

The general plan of the park had taken into consideration the necessity of removing the roadway from the dunes and keeping parking off the dunes. The access road and parking areas were to be built along the back of the beach (Little Harbour side) at approximately high water and about 160 feet back from the dune crest (Fig. 5). Since people on foot have a similar destructive impact on the dunes as cars (although to a lesser extent), access to the beach front was to be by means of raised boardwalks from the parking lots. These boardwalks were constructed in such a way as to allow for growth of the dune grass underneath.

In order to trap and hold the wind-blown sand, the breaks were fenced using spruce boughs on a frame made of 2 inch-by-4 inch lumber to approximately three feet in height. Boughs were readily available from local pulp-wood operations, and other material was available from lumber companies. The spruce bough fences are superior to snow fences for the following reasons: cheaper materials, greater adaptability, minimal metal residues left in the sand, availability of material the the fact that the boughs would mulch in to enhance the organic content of the sand.

Planting would utilize dune grass from unaffected back areas of the dune where the grass type was the same as at the dune front. This is not normally the case for stable dune systems, but was a symptom of the rapid deterioration of the beach. Grass would be planted six to nine inches deep before the grass came out of hibernation (i.e. turned green), but after any chance of frost damage had passed. Planting was scheduled for the first part of May when the above conditions would most likely be met. A nitrogen-rich fertilizer would be added, as this nutrient is most required by dune (Marram) grass.

Since the co-operation and interest of the public is essential to the success of any such program, plans for on-the-beach signing and slide shows for the high schools were made. It had been noted that high schools students made the greatest use of the beach. Signing was to be as natural looking as possible, yet be legible and weather resistant. The message was to be brief and signs placed by access boardwalks. Subtle crowd control was to be achieved by planting of parking lot boarders with wild rose bushes to keep people off the dunes and on the boardwalks. 


\section{PLANTING}

The planting method found most effective involved basically sod planting. Clumps of Marram grass (Ammophelia breviligulata) were dug up by spade and transferred to boxes. The clumps were not cleaned as recommended in many planting texts, but planted directly in holes about nine inches deep.

\section{RESULTS AND EFFECTIVENESS}

Dune Grass

Spring-planted dune grass, planted as late as the first week in June, showed good survival. By fall, $75 \%$ of a test plot was still healthy, but the $25 \%$ loss was not all due to natural causes. It was noted that dune buggy tracks had crossed the plot and, by careful examination, it was determined that two-thirds of the $25 \%$ loss was due to destruction by the dune buggies. Thus, overall, the survival was 908 the first year. By the following summer (August, 1976), expanded growth had increased the number of plants such that they were individually uncountable.

A test plot was planted in the fall (1975) and not aided with fertilizer. When re-checked in June 1976, it showed a 60 c survival; although, again, approximately three-quarters of the loss could be attributed to dune buggy tracks over the plot. It appears that fall planting would likely be as successful as spring planting, weather, etc., being comparable.

Dune grass planted in the areas of maximum sand movement accumulated sand to depths of over a foot, but on the average, accumulation was approximately six inches per year over most of the beach. Dune grass survived well when planted in as little as five inches of sand as opposed to the optimum nine inches.

\section{Brush Fencing}

Brush fencing unfortunately suffered fairly extensive vandalism initially. This was due mainly because it blocked access to the beach through the blowouts used by local dune buggy drivers. Thus, some. were knocked down and others burnt; in all, approximately 208 of the fencing was destroyed by July of 1975. Thiss fencing was re-built in September, fust prior to fall storms and survived very well except for natural causes.

These fences all filled in to their three-foot height in a matter of weeks, except for fences towards the western end of the beach. Fences at this end of the beach did not receive as much sand as the other fences, being the last fence in line to receive sand blown by prevailing northeast winds.

Northeast winds: and fall storms also combined to cause extra high tides. At the western end of the beach, the washover fan at maximum was only four feet above normal high tide. In October, 1975, one washover area re-flooded when the extra high tides of the fall and northeast winds caused the sea to over-flood the area by two feet. However, the effect was not as serious as might be expected, since brush fencing helped keep sand in place and even collected some. Damage to the fence was slight, about five feet being washed away.

\section{CONCLUSIONS}

The overall plan of the park greatly aided in the restoration of the beach, especially the removal of the road from the dunes and the construction of boardwalks. Public awareness and cooperation are invaluable, since they are the users of the facility. Most of the damage to dune grass, fencing and signing was by the public and resulted in destruction of approximately one-fifth of the restoration project. Non-survival from natural sources was one-tenth for dune grass and about one-fifth for washed-out fencing at the western end of the beach.

Both the dune grass and the fencing were very effective in trapping sand to fill in the blowouts. This, along with the boardwalks and parking lots, reduced the traffic over the dunes, allowing for natural processes of dune re-building to expand.

Over most of the beach, the system is rebuilding, assisted by the work described. Unfortunately, some problems still exist. One of the main ones is to devise a means of spreading the use of the beach out along its length in order to reduce the intense traffic at the mainland end. The swimming area which was at this end has been moved to the middle of the beach, but a canteen at the end of the beach still causes people to congregate on that portion of the beach and dunes. At the western end of the beach, repeated breachings are still occurring requiring heavy maintenance in planting and fencing.

\section{SELECTED BIBLIOGRAPHY}

BOWEN, A.J., The maintenance of beaches, Technical Report, Prepared for the Nova Scotia Environmental Control Council, July, 1975.

Canplan Consultants Itd. et al Melmerby Beach Provincial Park Provisional Master Plan. Prepared for Parks and Recreation Division, Department of Lands and Forests, Nova Scotia, March, 1974.

Illustrated Historical Atlas of Pictou County, Nova Scotia, J.S. Meacham and Co., 1879, pp. 52-53. 